\title{
Artificial light source selection in seaweed production: growth of seaweed and biosynthesis of photosynthetic pigments and soluble protein
}

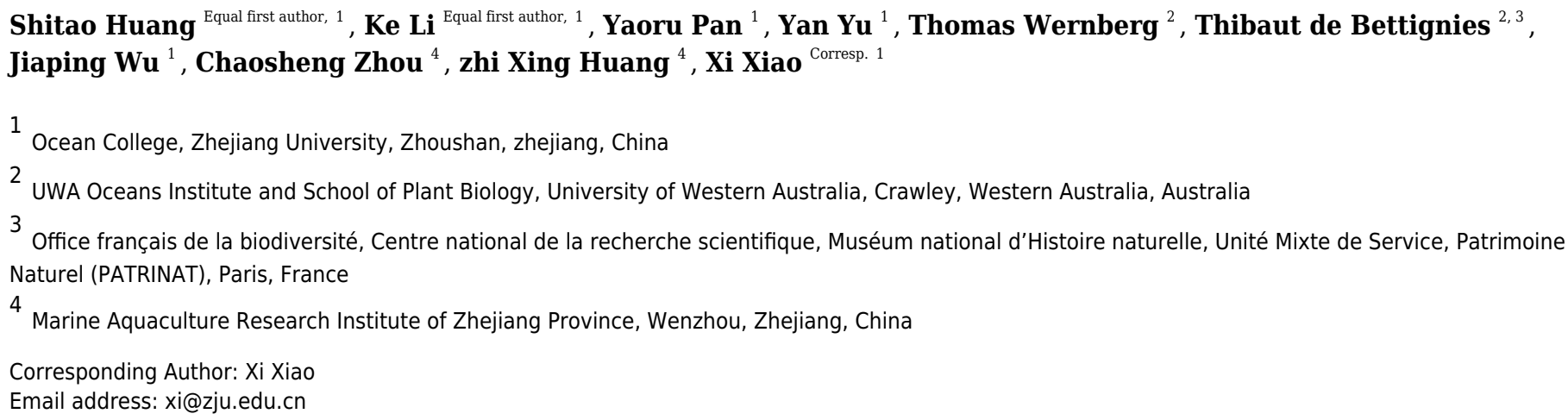

Seaweed growth is often limited by light. Artificial light supply has been well studied in terrestrial agriculture, however, much less is known about its effect in seaweed aquaculture. In this study, the effects of four artificial light sources (white, red, green, and blue LEDs light) on a brown alga Sargassum fusiforme and a green alga Ulva pertusa were investigated. Seaweed growth, accumulation of photosynthetic pigments (chlorophyll a and carotenoid), and soluble protein were evaluated. White LED light was the optimal supplementary light when cultivating Ulva pertusa and Sargassum fusiforme, because it promoted seaweed growth while maintaining protein production. Meanwhile, red LED was unfavored in the cultivation of $S$. fusiforme, as it affected the seaweed growth and has a lower residual energy ratio underneath the water. LEDs would be a promising supplementary light source for seaweed cultivation. 


\section{Artificial light source selection in seaweed}

2 production: growth of seaweed and biosynthesis of

3 photosynthetic pigments and soluble protein

4

5 Shitao Huang ${ }^{1 \mathrm{la}}$, Ke Li ${ }^{1 \mathrm{a}}$, Yaoru Pan ${ }^{1}$, Yan $\mathrm{Yu}^{1}$, Thomas Wernberg ${ }^{2}$, Thibaut de Bettignies ${ }^{23}$,

6 Jiaping $\mathrm{Wu}^{1}$, Chaosheng Zhou ${ }^{4}$, Zhixing Huang ${ }^{4}$, Xi Xiao ${ }^{1 *}$

7

$8{ }^{1}$ Ocean College, Zhejiang University, Zhoushan, Zhejiang, China

$9{ }^{2}$ UWA Oceans Institute and School of Plant Biology, University of Western Australia, Crawley,

10 Western Australia, Australia

$11{ }^{3}$ Service du Patrimoine Naturel, Museum National d'Histoire Naturelle, Paris, France

$12{ }^{4}$ Marine Aquaculture Research Institute of Zhejiang Province, Wenzhou, Zhejiang, China

a These two authors contributed equally to this paper:

Shitao Huang, Ke li

17 Zhoushan, Zhejiang, China

18 Email address: 21934033@zju.edu.cn, leeke0304@zju.edu.cn

*Corresponding Author:

21 Xi Xiao

22 Zhoushan, Zhejiang, China

23 Email address: $\underline{x i @ z j u . e d u . c n}$ 


\section{Abstract}

25 Seaweed growth is often limited by light. Artificial light supply has been well studied in

26

27

28

29

30

31

32

33

34

35

36

37

38

39

40

41

42

43

44

45

46

47

48

49

50

51

52

53

54

55

56

57

58

59

60

61

terrestrial agriculture, however, much less is known about its effect in seaweed aquaculture. In this study, the effects of four artificial light sources (white, red, green, and blue LEDs light) on a brown alga Sargassum fusiforme and a green alga Ulva pertusa were investigated. Seaweed growth, accumulation of photosynthetic pigments (chlorophyll $a$ and carotenoid), and soluble protein were evaluated. White LED light was the optimal supplementary light when cultivating Ulva pertusa and Sargassum fusiforme, because it promoted seaweed growth while maintaining protein production. Meanwhile, red LED was unfavored in the cultivation of S. fusiforme, as it affected the seaweed growth and has a lower residual energy ratio underneath the water. LEDs would be a promising supplementary light source for seaweed cultivation.

Keywords: light-emitting diodes (LEDs), pigment; soluble protein; light sources; seaweed.

\section{Introduction}

The coastal ecosystem provides a variety of ecosystem goods and services that support the sustainable development for human beings (Bennett et al., 2016; Mehvar et al., 2018; Wu et al., 2020). Among them, seaweeds cover a large area of the coastal zone, providing high-value ecosystem services (i.e. globally significant carbon fixation, absorb contaminants, etc.) and raw material for food, fertilizer, and pharmaceutical industries (Capuzzo et al., 2015; Duarte et al., 2017; Xiao et al., 2017, 2019a, 2021; Pan et al., 2018). However, human activities and global climate change are currently posing a high pressure on the coastal ecosystems (Xiao et al., 2015; Zhao et al., 2017; Smale et al., 2019; Huang et al., 2020, 2021; Tang et al., 2021). Natural seaweeds are facing the threat of ecological degradation (Xiao et al., 2019b; Xiao, Huang \& Holmer, 2020), and there is an increasing demand for large-scale seaweed aquaculture (Xiao et al., 2017).

Nevertheless, problems such as warming, high sediment load, epiphyte cover, disease, and fish grazing seriously affect the development of large-scale seaweed farming (Ateweberhan, Rougier \& Rakotomahazo, 2015). A fundamental factor affecting seaweed growth is light limitation (Xiao et al., 2019a). Modern mariculture with excessive fertilizer application retains a large number of nutrients and contaminants in seaweed cultivation area, increasing the turbidity of seawater (Lu, Wang \& Feng, 2017). Light availability, which is limited by water transparency, directly determines the photosynthesis activity of seaweeds and their biosynthesis ability, causing ecological and economic loss to seaweed farms (Orfanidis, 1992). For instance, Zhoushan Island in the East China Sea, situated at the mouth of the Yangzi River, is encountering turbid water, and seaweed cannot grow well in such coastal waters (Tseng, 1987). Light limitation may therefore also restrict the important ecological functions of seaweed farming, such as nitrogen and phosphorus removal (Matos et al., 2006; Abreu et al., 2011; Xiao

Peer) reviewing PDF | (2019:12:44139:3:0:NEW 1 Apr 2021) 
62 et al., 2017, 2019a). Hence, artificial lighting may be a solution to encourage seaweed growth

63 under a light-limitation situation (Xiao et al., 2017, 2019a).

64 Light-emitting diodes (LEDs) produce monochromatic light in an energy-efficient way,

65

66

67

68

69

70

71

72

73

74

75

76

77

78

79

80

81

82

83

84

85

86

87

88

89

90

91

92

93

94

95

96

97

98

99

suggesting their potential to provide supplementary light for seaweed growth (Bourget, 2008;

Kim et al., 2015). By filtering fluorescent light with band-pass filters, monochromatic lights have been produced to promote seaweed growth, and their influence has been tested on several seaweed species (Figueroa \& Niell, 1990; Figueroa et al., 1995; Korbee, Figueroa \& Aguilera, 2005; Kim et al., 2015; Bonomi Barufi, Figueroa \& Plastino, 2015). In general, compared to fluorescent light culturing, the seaweed growth rate could be increased by $10-60 \%$ under suitable LED light conditions (Schulze et al., 2016; Kim, Choi \& Lee, 2019; Gong, Liu \& Zou, 2020; Öztaşkent \& Ak, 2020). However, although LED light has been proposed as a light source for Gracilaria cultivation (Kim et al., 2015; Bonomi Barufi, Figueroa \& Plastino, 2015), its influence on a broader variety of seaweed species and their biosynthesis remains poorly understood. Besides, different wavelengths of lights vary in their ability to penetrate water. For instance, in general, red light is most likely to be absorbed by water, and thus blue and green light can go deeper than red light (Chiang, Chen \& Chen, 2011). Therefore, there is an urgent need to further test the influence of LED light on the growth and biosynthesis of seaweed.

In this experiment, white, blue, green and red LED light were tested as artificial light sources to support the cultivation of two common and economically important seaweed - Ulva pertusa and Sargassum fusiforme. We assessed the seaweed growth, photosynthetic pigments, and soluble protein accumulation. Biomass accumulation and lighting-harvesting efficiency are important factors in seaweed cultivation. Meanwhile, seaweed proteins are essential for their biological processes and may become important food sources (Cai et al., 2005; Postma et al., 2018). Our results will facilitate the selection of supplementary artificial light sources for seaweed cultivation.

\section{Materials \& Methods}

\section{Seaweed species and cultivation}

The juveniles of two seaweed species, Sargassum fusiforme, and Ulva pertusa, were collected from Dongtou Island, Wenzhou City, Zhejiang Province, China (27 51'42" N, $\left.121^{\circ} 11^{\prime} 06^{\prime \prime} \mathrm{E}\right)$. For acclimation, all the collected seaweeds were maintained in glass jars containing filtered, sterile natural seawater (33\%), and the temperature of seawater was controlled at $16^{\circ} \mathrm{C}$ by a chiller (LS16-600, JLLN, Shenzhen, China). Illumination was provided by fluorescent lamps (120 $\mu \mathrm{mol}$ photons $\mathrm{m}^{-2} \mathrm{~s}^{-1}, 12 \mathrm{~h}$ of light followed by $12 \mathrm{~h}$ of darkness). After 3 days of acclimation, healthy individual seaweeds were selected and used in the following experiments.

\section{Light sources}

Four LEDs emitting white, red, green, and blue light were used as artificial light sources for seaweed cultivation, providing $120 \mu \mathrm{mol}$ photons $\mathrm{m}^{-2} \mathrm{~s}^{-1}$ on the surface of seaweed thalli. The LED lighting system was assembled in PVC tubes (height: $25 \mathrm{~cm}$, diameter: $20 \mathrm{~cm}$ ), with

Peer] reviewing PDF | (2019:12:44139:3:0:NEW 1 Apr 2021) 
100 flexible LED light belts (length: $3 \mathrm{~m}$ ) affixed to the inner walls of each PVC tubes (Fig. 1). All 101 the LED lighting diodes (Opple Co. Ltd., Shanghai, China) were driven by a 220V power supply. 102 The light was supplied for 12 hours every day from 6:00 a.m to 6:00 p.m. Light spectra were 103 measured with an optical spectrum analyzer (CMS-2S, Inventfine Co. Ltd., Hangzhou, China). 104 Light intensity was measured using an MQ-200 Quantum Separate Sensor (Apogee Instruments, 105 USA). Residual energy ratio (Rer) underwater was measured following Chiang's method (Table 106 S2) (Chiang, Chen \& Chen, 2011). Among the four LED lights, the red LED light has the lowest 107 Rer value, followed by the white, green, and blue light, respectively (Table S2).

\section{Emission spectral distribution of light sources}

109 The peak wavelengths of the red, green, and blue LEDs were $632 \mathrm{~nm}, 517 \mathrm{~nm}$, and $462 \mathrm{~nm}$, 110 respectively, and all the peaks are narrow $(80-100 \mathrm{~nm}$ ) (Fig. 2). White LED had a continuous 111 spectrum with two peaks in the blue and green light region.

\section{Light incubation experiments}

113 The cultivation lasted for 18 days. Five juvenile individual seaweeds (approx. $5 \mathrm{~g}$ fresh weight) were placed into one cylindrical plastic bottle $(1000 \mathrm{ml}$, diameter: $100 \mathrm{~mm})$. Three replicate bottles were placed inside the PVC tubes for light treatments (Fig. 1) (Kim et al., 2015). In total, 15 juveniles of $U$. pertus and 12 juveniles of $S$. fusiforme were set in a PVC tube. The LED lights were controlled independently. During the experimental period, both S. fusiforme and U. pertusa were cultivated in filtered and sterile natural seawater. The nutrients, phosphate $\left(\mathrm{PO}_{4}{ }^{3-}\right)$ and nitrate $\left(\mathrm{NO}_{3}{ }^{-}\right)$were renewed every second day. The $\mathrm{PO}_{4}{ }^{3-}$ and $\mathrm{NO}_{3}{ }^{-}$concentrations of seawater were $15 \mu \mathrm{mol} \mathrm{L}^{-1}$ and $150 \mu \mathrm{mol} \mathrm{L}^{-1}$, respectively. The seawater was sufficiently aerated by an air pump. The temperature in the aquarium was kept at $16^{\circ} \mathrm{C}$.

\section{Growth}

123

124

125

126

127

Specific growth rate (SGR) was calculated following the method used in our previous study (Xiao et al., 2015):

$$
S G R=\ln \left(\frac{W_{t}}{W_{0}}\right) \times t^{-1} \times 100
$$

where $W_{0}$ is the initial algal biomass, and $W_{t}$ is the algal biomass after $t$ days of cultivation. Fresh weights (FW) of S. fusiforme and U. pertusa were measured every second day.

\section{Photosynthetic pigment and soluble protein}

The photosynthetic pigment Chlorophyll $a$ and carotenoid content were measured. Chlorophyll $a$ was extracted using acetone (90\%) neutralized with sodium carbonate, as described in Jeffrey \& Humphrey (1975). Carotenoid concentrations were detected following Seely, Duncan, and Vidaver (Seely, Duncan \& Vidaver, 1972). Chlorophyll $a$ and carotenoid were measured every second day by spectrophotometer (Inesa 722S, Shanghai, China). The soluble protein concentrations were also determined spectrophotometrically at $595 \mathrm{~nm}$ by Coomassie brilliant blue method every second day (Bradford, 1976). 


\section{Data analysis}

137 Differences between light treatments were tested for each species separately using one-way

138

139

140

141

142

143

144

145

146

147

148

149

150

151

152

153

154

155

156

157

158

159

160

161

162

163

164

165

166

167

168

169

170

171 ANOVA with a significant level of $p<0.05$. Tukey's test was used for the post hoc test. Data normality was checked by the shapiro-wilk test and variances homogeneity were checked by Levene's test. Differences between data that did not pass the normality test were analyzed by Kruskal-Wallis $H$ test (non-parametric). Data with differences that did not pass Levene's test were analyzed by Welch's ANOVA, where the Games-Howell test was used for post hoc test. Statistical tests were performed with SPSS (version 19.0).

\section{Results}

\section{Specific growth rate}

For both seaweed species (Ulva pertusa and Sargassum fusiforme), white-LED light stimulated seaweed growth and the light colors of LEDs differed in their influences on seaweed growth. The white light stimulated the growth of $U$. pertusa (average SGR $=5.16 \pm 0.88 \% \mathrm{~d}^{-1}$ ) significantly, compared to the green light $\left(4.07 \pm 0.64 \% \mathrm{~d}^{-1}\right)($ Fig.3, $\mathrm{p}<0.05)$. As for S. fusiforme, SGR decreased following the sequence of white LED light $\left(3.21 \pm 1.10 \% \mathrm{~d}^{-1}\right)>$ green and blue LED light $\left(2.44 \pm 1.13\right.$ and $\left.2.35 \pm 0.66 \% \mathrm{~d}^{-1}, \mathrm{p}>0.05\right)>\operatorname{red}$ LED light $\left(1.34 \pm 0.39 \% \mathrm{~d}^{-1}, \mathrm{p}<\right.$ $0.05)$.

\section{Photosynthetic pigments and soluble protein}

The LED lights induced changes in pigments and soluble protein synthesis in the two seaweed species. For instance, the Chl $a$ concentration of $U$. pertusa treated with red LED light $(1.21 \pm$ $\left.0.15 \mathrm{mg} \mathrm{g}^{-1}\right)$ was higher than those treated with white $\left(0.92 \pm 0.19 \mathrm{mg} \mathrm{g}^{-1}\right.$, adjusted $\mathrm{p}=0.004, \mathrm{p}$ $=0.001)$, green $\left(1.00 \pm 0.20 \mathrm{mg} \mathrm{g}^{-1}\right.$, adjusted $\left.\mathrm{p}=0.040, \mathrm{p}=0.007\right)$ and blue LED lights $(1.06 \pm$ $0.13 \mathrm{mg} \mathrm{g}^{-1}$, adjusted $\mathrm{p}=0.491, \mathrm{p}=0.082$ ) (Fig. 4). For $S$. fusiforme, Chl $a$ concentration of the seaweed were the same in all the light treatments. Carotenoid concentrations shared similar levels in different LED groups for both U. pertusa and $S$. fusiforme ( $\mathrm{p}>0.05)$. The concentrations of soluble protein showed no significant difference among four LED groups in $U$. pertusa and S. fusiforme (Fig. 5).

\section{Discussion}

\section{Light driven shifts in seaweed growth}

For both seaweed species $U$. pertusa (green algae) and $S$. fusiforme (brown algae), the experimental seedlings achieved the highest growth rate under white LED lighting, which is consistent with previous studies (Tovar et al., 2000; Kim et al., 2015). This may be partially explained by the broad light wavelengths of white light (from $430 \mathrm{~nm}$ to $630 \mathrm{~nm}$ ) (Fig. 2). White LED light, with the ability to provide spectrum comparable of sunlight (Glemser et al., 2016), is capable of supporting $\mathrm{C}$ and $\mathrm{N}$ metabolism in seaweeds (Tsekos et al., 2002; Korbee, Figueroa \& Aguilera, 2005). White LED light with a broad continuous emission spectrum, is also providing 
172 a higher luminous efficiency compared to a fluorescent white-light source (Pimputkar et al., 173 2009). S. fusiforme cultivated under red LED lights had a significantly lower growth rate 174 compared to those treated with white LED lights. S. fusiforme contains fucoxanthin, one of the 175 brown algae carotenoids that plays an important role in photosynthesis (Terasaki et al., 2005; 176 Xiao et al., 2012). The main absorption peaks of fucoxanthin are in the blue region (about 455 $177 \mathrm{~nm}$ ) (Wang et al., 2005). Thus, red light is not likely to be utilized at high efficiency by $S$.

178 fusiforme. Another species of brown algae Sargassum horneri also showed slower growth than 179 the individuals cultivated in white or blue LED lights (Miki et al., 2017). Interestingly, red LED 180 light has been widely applied in the cultivation of microalgae and terrestrial plants (Goins et al., 181 1997; Poudel, Kataoka \& Mochioka, 2008) (see also Table S1). However, a negative influence of red LED light on $S$. fusiforme growth was found in our experiment. This hinted again, the importance to further investigate more seaweed species since the influence of light quality appeared to be highly species-dependent.

Through the 18 days of cultivation, $U$. pertusa seemed to maintain a relatively fast and stable growth under all the LED lights with constant growth rates, while $S$. fusiforme held a higher growth rate in the last days than the earlier days (Fig. 3). Ulva species (i.e. U. lactuca and $U$. prolifera) grow faster than many other macroalgal species (Pedersen, Borum \& Fotel, 2010; Tang et al., 2021). Also, the simple morphology of $U$. pertusa leads to an easier adaptation to the environment (including changes in the light condition). On the contrary, S. fusiforme may take a longer time for adaptation when cultured in changed light conditions (Fig. 3). Another brown alga Sargassum horneri, which was morphologically similar to $S$. fusiforme, showed a similar growth pattern when cultured in LED lights (Miki et al., 2017). The thalli from S. horneri were found to absorb red light in low efficiency, we suspect that the utilization rate of red light may also be lower for S. fusiforme thalli, leading to a lower growth rate under red LED lights (Matsui, Ohgai \& Murase, 1994; Miki et al., 2017).

\section{Light-driven shifts in seaweed biosynthesis}

199

200

201

202

203

204

205

206

207

208

209

210
The accumulation of photosynthetic pigments and soluble protein in U. pertusa and S. fusiforme were also influenced by light sources. Chl $a$ concentration was significantly higher in U. pertusa under red LED light as compared to white and green LED lights. Similar to our findings, several other green algae Ulva prolifera and Ulva lactuca held higher Chl $a$ content in red LED cultivation compared to white and blue LED lights (Takada et al., 2011; Gong, Liu \& Zou, 2020). However, $U$. pertusa was found to synthesize less Chl $a$ and form smaller chloroplast under red light, as compared to blue and white lights (Muthuvelan, Noro \& Nakamura, 2002; Le et al., 2018). The higher Chl $a$ concentration per fresh weight of $U$. pertusa may be derived from the restrained biomass accumulation under red light.

As for carotenoid and soluble protein content, no significant difference was found among the four light treatments for both $S$. fusiforme and U. pertusa in our study. Previously, the red light was found to promote carotenoid synthesis in a green algae Dunaliella salina to reduce reactive oxygen species formation and increase anti-oxidant level (Xu \& Harvey, 2019a,b). 


\section{Seaweed cultivation in fields using supplementary LED lights}

212 Seaweeds play an important role in food and feed supply (Makkar et al., 2016). LED lights could

213 stimulate the growth and increase the yield of specific seaweeds as compared to traditional

214 fluorescent light (Kim, Choi \& Lee, 2019; Gong, Liu \& Zou, 2020). The growth and biochemical

215 composition of seaweed were affected by the light quality, indicating the potential for using

216 artificial light to increase the yield and proportion of high-value biomolecules in seaweed

217 aquaculture (Table S1). There are plenty of commercially available LED devices, and

218 underwater LED lighting has been developed for many years, which makes LED cultivation

219 systems easy to be established for both land and offshore seaweed cultivation (Hardy et al., 2008;

220 Shen et al., 2013). Our indoor experiment showed that white LEDs were favored in the

221

222

223

224

225

226

227

228

229

230

231

232

233

234

235

236

237

238

239

240

241

242

243

244

245

246

247

248 cultivation of $U$. pertusa and $S$. fusiforme because white LED promoted seaweed growth while protein production was maintained at a constant level. White LED has also a relatively good ability to penetrate underwater (Table S2). Nevertheless, the turbidity of water is still an important factor to be considered in fields. For seaweed cultivation on lands, water renewal or flow water are usually applied, so it is relatively easy to keep the water clean. But for seaweed growing in a natural water body, such as for seaweed-based ecosystem restoration, turbidity and other environmental factors need to be considered in the future study.

\section{Conclusions}

To summarize, this investigation highlighted the potential of the supplementary LED light source in seaweed cultivation. The results indicated that the effects of artificial light on seaweed, including the growth rate, photosynthetic pigments, and soluble protein are highly speciesdependent. Therefore, we propose that manipulating the artificial light source for seaweed research and seedling industries is a promising venture.

\section{Acknowledgements}

This study was supported by the Major Science and Technology Program for Water Pollution Control and Treatment (2018ZX07208-009), National Natural Science Foundation of China (grant no. $21876148 \& 21677122$ ), the International Science \& Technology Cooperation Program of China (grant no. 2015DFS01410). TW was supported by the Australian Research Council (DP160100114). We thank Peng Zhang and Yining Zhang at Marine Aquaculture Research Institute of Zhejiang Province for guidance in seaweed cultivation.

\section{References}

Abreu MH, Pereira R, Yarish C, Buschmann AH, Sousa-Pinto I. 2011. IMTA with Gracilaria vermiculophylla: Productivity and nutrient removal performance of the seaweed in a landbased pilot scale system. Aquaculture 312:77-87. DOI: 10.1016/j.aquaculture.2010.12.036. Ateweberhan M, Rougier A, Rakotomahazo C. 2015. Influence of environmental factors and farming technique on growth and health of farmed Kappaphycus alvarezii (cottonii) in south-west Madagascar. Journal of Applied Phycology 27:923-934. DOI: 10.1007/s10811014-0378-3. 
249

250

251

252

253

254

255

256

257

258

259

260

261

262

263

264

265

266

267

268

269

270

271

272

273

274

275

276

277

278

279

280

281

282

283

284

285

286

287

288

289

290

291

292

293
Bennett S, Wernberg T, Connell SD, Hobday AJ, Johnson CR, Poloczanska ES. 2016. The 'Great Southern Reef': social, ecological and economic value of Australia's neglected kelp forests. Marine and Freshwater Research 67:47-56. DOI: 10.1071/MF15232.

Bonomi Barufi J, Figueroa FL, Plastino EM. 2015. Effects of light quality on reproduction, growth and pigment content of Gracilaria birdiae (Rhodophyta: Gracilariales). Scientia Marina 79:15-24. DOI: 10.3989/scimar.04049.12A.

Bourget CM. 2008. An Introduction to Light-emitting Diodes. HortScience 43:1944-1946. DOI: 10.21273/HORTSCI.43.7.1944.

Bradford MM. 1976. A rapid and sensitive method for the quantitation of microgram quantities of protein utilizing the principle of protein-dye binding. Analytical Biochemistry 72:248254. DOI: https://doi.org/10.1016/0003-2697(76)90527-3.

Cai HJ, Tang XX, Zhang PY, Yang Z. 2005. Effects of UV-B radiation on the growth, physiological and biochemical characteristics of Ulva pertusa Kjellman. Sci Technol Eng 5:1671-1815.

Capuzzo E, Stephens D, Silva T, Barry J, Forster RM. 2015. Decrease in water clarity of the southern and central North Sea during the 20th century. Global Change Biology 21:22062214. DOI: $10.1111 / \mathrm{gcb} .12854$.

Chiang JY, Chen Y-C, Chen Y-F. 2011. Underwater Image Enhancement: Using Wavelength Compensation and Image Dehazing (WCID). In: Blanc-Talon J, Kleihorst R, Philips W, Popescu D, Scheunders P eds. Lecture Notes in Computer Science (including subseries Lecture Notes in Artificial Intelligence and Lecture Notes in Bioinformatics). Berlin, Heidelberg: Springer Berlin Heidelberg, 372-383. DOI: 10.1007/978-3-642-23687-7_34.

Duarte CM, Wu J, Xiao X, Bruhn A, Krause-Jensen D. 2017. Can Seaweed Farming Play a Role in Climate Change Mitigation and Adaptation? Frontiers in Marine Science 4. DOI: 10.3389/fmars.2017.00100.

Figueroa FL, Aguilera J, Jimenez C, Vergara JJ, Robles MD, Niell F. 1995. Growth, pigment synthesis and nitrogen assimilation in the red alga Porphyra sp (Bangiales, Rhodophyta) under blue and red light. Scientia Marina 59:9-20.

Figueroa FL, Niell FX. 1990. Effects of light quality on chlorophyll and biliprotein accumulation in seaweeds. Marine Biology 104:321-327. DOI: 10.1007/BF01313274.

Glemser M, Heining M, Schmidt J, Becker A, Garbe D, Buchholz R, Brück T. 2016. Application of light-emitting diodes (LEDs) in cultivation of phototrophic microalgae: current state and perspectives. Applied Microbiology and Biotechnology 100:1077-1088. DOI: 10.1007/s00253-015-7144-6.

Goins GD, Yorio NC, Sanwo MM, Brown CS. 1997. Photomorphogenesis, photosynthesis, and seed yield of wheat plants grown under red light-emitting diodes (LEDs) with and without supplemental blue lighting. Journal of Experimental Botany 48:1407-1413. DOI: 10.1093/jxb/48.7.1407.

Gong J, Liu Z, Zou D. 2020. Growth and photosynthetic characteristics of Gracilaria lemaneiformis (Rhodophyta) and Ulva lactuca (Chlorophyta) cultured under fluorescent light and different LED light. Journal of Applied Phycology. DOI: 10.1007/s10811-02002151-y.

Hardy KR, Olsson MS, Lakin BP, Steeves KA, Sanderson JR, Simmons JE, Weber PA. 2008. Advances in High Brightness Light Emitting Diodes in underwater applications. In: OCEANS 2008. 1-5. DOI: 10.1109/OCEANS.2008.5152008. 
294

295

296

297

298

299

300

301

302

303

304

305

306

307

308

309

310

311

312

313

314

315

316

317

318

319

320

321

322

323

324

325

326

327

328

329

330

331

332

333

334

335

336

337

338

339

Huang Y, Xiao X, Effiong K, Xu C, Su Z, Hu J, Jiao S, Holmer M. 2021. New Insights into the Microplastic Enrichment in the Blue Carbon Ecosystem: Evidence from Seagrass Meadows and Mangrove Forests in Coastal South China Sea. Environmental Science \& Technology. DOI: $10.1021 /$ acs.est.0c07289.

Huang Y, Xiao X, Xu C, Perianen YD, Hu J, Holmer M. 2020. Seagrass beds acting as a trap of microplastics - Emerging hotspot in the coastal region? Environmental Pollution 257:113450. DOI: 10.1016/j.envpol.2019.113450.

Jeffrey SW, Humphrey GF. 1975. New spectrophotometric equations for determining chlorophylls a, b, c1 and c2 in higher plants, algae and natural phytoplankton. Biochemie und Physiologie der Pflanzen 167:191-194. DOI: https://doi.org/10.1016/S00153796(17)30778-3.

Kim JH, Choi SJ, Lee S. 2019. Effects of temperature and light on photosynthesis and growth of red alga Pyropia dentata (Bangiales, Rhodophyta) in a conchocelis phase. Aquaculture 505:167-172. DOI: 10.1016/j.aquaculture.2019.02.058.

Kim JK, Mao Y, Kraemer G, Yarish C. 2015. Growth and pigment content of Gracilaria tikvahiae McLachlan under fluorescent and LED lighting. Aquaculture 436:52-57. DOI: https://doi.org/10.1016/j.aquaculture.2014.10.037.

Korbee N, Figueroa FL, Aguilera J. 2005. Effect of light quality on the accumulation of photosynthetic pigments, proteins and mycosporine-like amino acids in the red alga Porphyra leucosticta (Bangiales, Rhodophyta). Journal of Photochemistry and Photobiology B: Biology 80:71-78. DOI: https://doi.org/10.1016/j.jphotobiol.2005.03.002.

Le B, Shin J-A, Kang M-G, Sun S, Yang SH, Chung G. 2018. Enhanced growth rate and ulvan yield of Ulva pertusa using light-emitting diodes (LEDs). Aquaculture International 26:937-946. DOI: 10.1007/s10499-018-0260-4.

Lu X-X, Wang Z-H, Feng J. 2017. Sedimentary records of recent anthropogenic eutrophication and metal contamination in Zhelin Bay, an important mariculture area in Southern China. Marine Pollution Bulletin 114:1118-1124. DOI: https://doi.org/10.1016/j.marpolbul.2016.10.036.

Makkar HPS, Tran G, Heuzé V, Giger-Reverdin S, Lessire M, Lebas F, Ankers P. 2016. Seaweeds for livestock diets: A review. Animal Feed Science and Technology 212:1-17. DOI: https://doi.org/10.1016/j.anifeedsci.2015.09.018.

Matos J, Costa S, Rodrigues A, Pereira R, Sousa Pinto I. 2006. Experimental integrated aquaculture of fish and red seaweeds in Northern Portugal. Aquaculture 252:31-42. DOI: https://doi.org/10.1016/j.aquaculture.2005.11.047.

Matsui T, Ohgai M, Murase N. 1994. The Effects of Light Quality and Quantity on Germling and Thallus Growth in Sargassum horneri and S. patens. NIPPON SUISAN GAKKAISHI 60:727-733. DOI: 10.2331/suisan.60.727.

Mehvar S, Filatova T, Dastgheib A, De Ruyter van Steveninck E, Ranasinghe R. 2018. Quantifying Economic Value of Coastal Ecosystem Services: A Review. Journal of Marine Science and Engineering 6. DOI: 10.3390/jmse6010005.

Miki O, Okumura C, Marzuki M, Tujimura Y, Fujii T, Kosugi C, Kato T. 2017. Contrasting effects of blue and red LED irradiations on the growth of Sargassum horneri during the germling and immature stages. Journal of Applied Phycology 29:1461-1469. DOI: 10.1007/s10811-016-1026-X.

Muthuvelan B, Noro T, Nakamura K. 2002. Effect of light quality on the cell integrity in marine alga Ulva pertusa (Chlorophyceae). Indian Journal of Marine Sciences 31.

Peer] reviewing PDF | (2019:12:44139:3:0:NEW 1 Apr 2021) 
340

341

342

343

344

345

346

347

348

349

350

351

352

353

354

355

356

357

358

359

360

361

362

363

364

365

366

367

368

369

370

371

372

373

374

375

376

377

378

379

380

381

382

383

384

385

Orfanidis S. 1992. Light requirements for growth of six shade-acclimated Mediterranean macroalgae. Marine Biology 112:511-515. DOI: 10.1007/BF00356298.

Öztaşkent C, Ak İ. 2020. Effect of LED light sources on the growth and chemical composition of brown seaweed Treptacantha barbata. Aquaculture International. DOI: 10.1007/s10499020-00619-9.

Pan Y, Wernberg T, de Bettignies T, Holmer M, Li K, Wu J, Lin F, Yu Y, Xu J, Zhou C, Huang Z, Xiao X. 2018. Screening of seaweeds in the East China Sea as potential bio-monitors of heavy metals. Environmental Science and Pollution Research 25:16640-16651. DOI: 10.1007/s11356-018-1612-3.

Pedersen MF, Borum J, Fotel FL. 2010. Phosphorus dynamics and limitation of fast-and slowgrowing temperate seaweeds in Oslofjord, Norway. Marine Ecology Progress Series 399:103-115. DOI: 10.3354/meps08350.

Pimputkar S, Speck JS, DenBaars SP, Nakamura S. 2009. Prospects for LED lighting. Nature Photonics 3:180.

Postma PR, Cerezo-Chinarro O, Akkerman RJ, Olivieri G, Wijffels RH, Brandenburg WA, Eppink MHM. 2018. Biorefinery of the macroalgae Ulva lactuca: extraction of proteins and carbohydrates by mild disintegration. Journal of Applied Phycology 30:1281-1293. DOI: 10.1007/s10811-017-1319-8.

Poudel PR, Kataoka I, Mochioka R. 2008. Effect of red- and blue-light-emitting diodes on growth and morphogenesis of grapes. Plant Cell, Tissue and Organ Culture 92:147-153. DOI: $10.1007 / \mathrm{s} 11240-007-9317-1$.

Schulze PSC, Pereira HGC, Santos TFC, Schueler L, Guerra R, Barreira LA, Perales JA, Varela JCS. 2016. Effect of light quality supplied by light emitting diodes (LEDs) on growth and biochemical profiles of Nannochloropsis oculata and Tetraselmis chuii. Algal Research 16:387-398. DOI: 10.1016/j.algal.2016.03.034.

Seely GR, Duncan MJ, Vidaver WE. 1972. Preparative and analytical extraction of pigments from brown algae with dimethyl sulfoxide. Marine Biology 12:184-188. DOI: 10.1007/BF00350754.

Shen SC, Huang HJ, Chao CC, Huang MC. 2013. Design and analysis of a high-intensity LED lighting module for underwater illumination. Applied Ocean Research 39:89-96. DOI: https://doi.org/10.1016/j.apor.2012.10.006.

Smale DA, Wernberg T, Oliver ECJ, Thomsen M, Harvey BP, Straub SC, Burrows MT, Alexander V L, Benthuysen JA, Donat MG, Feng M, Hobday AJ, Holbrook NJ, PerkinsKirkpatrick SE, Scannell HA, Sen Gupta A, Payne BL, Moore PJ. 2019. Marine heatwaves threaten global biodiversity and the provision of ecosystem services. Nature Climate Change 9:306+. DOI: 10.1038/s41558-019-0412-1.

Takada J, Murase N, Abe M, Noda M, Suda Y. 2011. Growth and Photosynthesis of Ulva prolifera under Different Light Quality from Light Emitting Diodes (LEDs). Aquaculture Science 59:101-107. DOI: 10.11233/aquaculturesci.59.101.

Tang T, Effiong K, Hu J, Li C, Xiao X. 2021. Chemical Prevention and Control of the Green Tide and Fouling Organism Ulva: Key Chemicals, Mechanisms, and Applications . Frontiers in Marine Science 8:87.

Terasaki M, Hirose A, Narayan B, Baba Y, Kawagoe C, Yasui H, Saga N, Hosokawa M, Miyashita K. 2005. Evaluation of recoverable functional lipid components of several brown seaweeds (phaeophyta) from Japan with special reference to fucoxanthin and fucosterol contents. Journal of Phycology 45:1009-1015. DOI: 10.1111/j.1744-7909.2005.00054.x. 
386

387

388

389

390

391

392

393

394

395

396

397

398

399

400

401

402

403

404

405

406

407

408

409

410

411

412

413

414

415

416

417

418

419

420

421

422

423

424

425

426

427

428

429

430

431

Tovar A, Moreno C, Mánuel-Vez MP, García-Vargas M. 2000. Environmental impacts of intensive aquaculture in marine waters. Water Research 34:334-342. DOI: https://doi.org/10.1016/S0043-1354(99)00102-5.

Tsekos I, Niell FX, Aguilera J, López-Figueroa F, Delivopoulos SG. 2002. Ultrastructure of the vegetative gametophytic cells of Porphyra leucosticta (Rhodophyta) grown in red, blue and green light. Phycological Research 50:251-264. DOI: 10.1046/j.1440-1835.2002.00284.x.

Tseng CK. 1987. Laminaria mariculture in China. In: Doty MS, Caddy JF, Santelices B eds. Case Studies of Seven Commercial Seaweed Resources. Rome: Food and Agriculture Organization,.

Wang WJ, Wang GC, Zhang M, Tseng CK. 2005. Isolation of fucoxanthin from the rhizoid of Laminaria japonica Aresch. Journal of Integrative Plant Biology 47:1009-1015. DOI: 10.1111/j.1744-7909.2005.00054.x.

Wu J, Zhang H, Pan Y, Krause-Jensen D, He Z, Fan W, Xiao X, Chung I, Marbà N, Serrano O, Rivkin RB, Zheng Y, Gu J, Zhang X, Zhang Z, Zhao P, Qiu W, Chen G, Duarte CM. 2020. Opportunities for blue carbon strategies in China. Ocean \& Coastal Management 194:105241. DOI: https://doi.org/10.1016/j.ocecoaman.2020.105241.

Xiao X, Agusti S, Lin F, Li K, Pan Y, Yu Y, Zheng Y, Wu J, Duarte CM. 2017. Nutrient removal from Chinese coastal waters by large-scale seaweed aquaculture. Scientific Reports $7: 46613$.

Xiao X, Agusti S, Lin F, Xu C, Yu Y, Pan Y, Li K, Wu J, Duarte CM. 2019a. Resource (Light and Nitrogen) and Density-Dependence of Seaweed Growth. Frontiers in Marine Science $6: 618$

Xiao X, Agustí S, Pan Y, Yu Y, Li K, Wu J, Duarte CM. 2019b. Warming Amplifies the Frequency of Harmful Algal Blooms with Eutrophication in Chinese Coastal Waters. Environmental Science \& Technology 53:13031-13041. DOI: 10.1021/acs.est.9b03726.

Xiao X, Agustí S, Yu Y, Huang Y, Chen W, Hu J, Li C, Li K, Wei F, Lu Y, Xu C, Chen Z, Liu $\mathrm{S}$, Zeng J, Wu J, Duarte CM. 2021. Seaweed farms provide refugia from ocean acidification. Science of The Total Environment 776:145192. DOI: 10.1016/j.scitotenv.2021.145192.

Xiao X, de Bettignies T, Olsen YS, Agusti S, Duarte CM, Wernberg T. 2015. Sensitivity and Acclimation of Three Canopy-Forming Seaweeds to UVB Radiation and Warming. PLoS One 10:e143031.

Xiao X, Huang Y, Holmer M. 2020. Current trends in seagrass research in China (2010-2019). Aquatic Botany 166:103266. DOI: https://doi.org/10.1016/j.aquabot.2020.103266.

Xiao X, Si X, Yuan Z, Xu X, Li G. 2012. Isolation of fucoxanthin from edible brown algae by microwave-assisted extraction coupled with high-speed countercurrent chromatography. Journal of Separation Science 35:2313-2317. DOI: 10.1002/jssc.201200231.

Xu Y, Harvey PJ. 2019a. Carotenoid Production by Dunaliella salina under Red Light. Antioxidants 8. DOI: 10.3390/antiox8050123.

$\mathrm{Xu}$ Y, Harvey PJ. 2019b. Red Light Control of $\beta$-Carotene Isomerisation to 9-cis $\beta$-Carotene and Carotenoid Accumulation in Dunaliella salina. Antioxidants 8. DOI: 10.3390/antiox 8050148.

Zhao H, Cao Z, Liu X, Zhan Y, Zhang J, Xiao X, Yang Y, Zhou J, Xu J. 2017. Seasonal variation, flux estimation, and source analysis of dissolved emerging organic contaminants in the Yangtze Estuary, China. Marine Pollution Bulletin 125:208-215. DOI: 10.1016/j.marpolbul.2017.08.034. 
Figure 1

Experimental settings of LED culture system for $U$. pertusa and $S$. fusiforme

W, R, G, B represent white, red, green, blue LED light treatments. The LED lighting system was assembled in white PVC tubes (height: $25 \mathrm{~cm}$, diameter: $20 \mathrm{~cm}$ ), with flexible rope LED lights (rope length is $3 \mathrm{~m}$ ) affixed to the inner walls of each PVC tubes
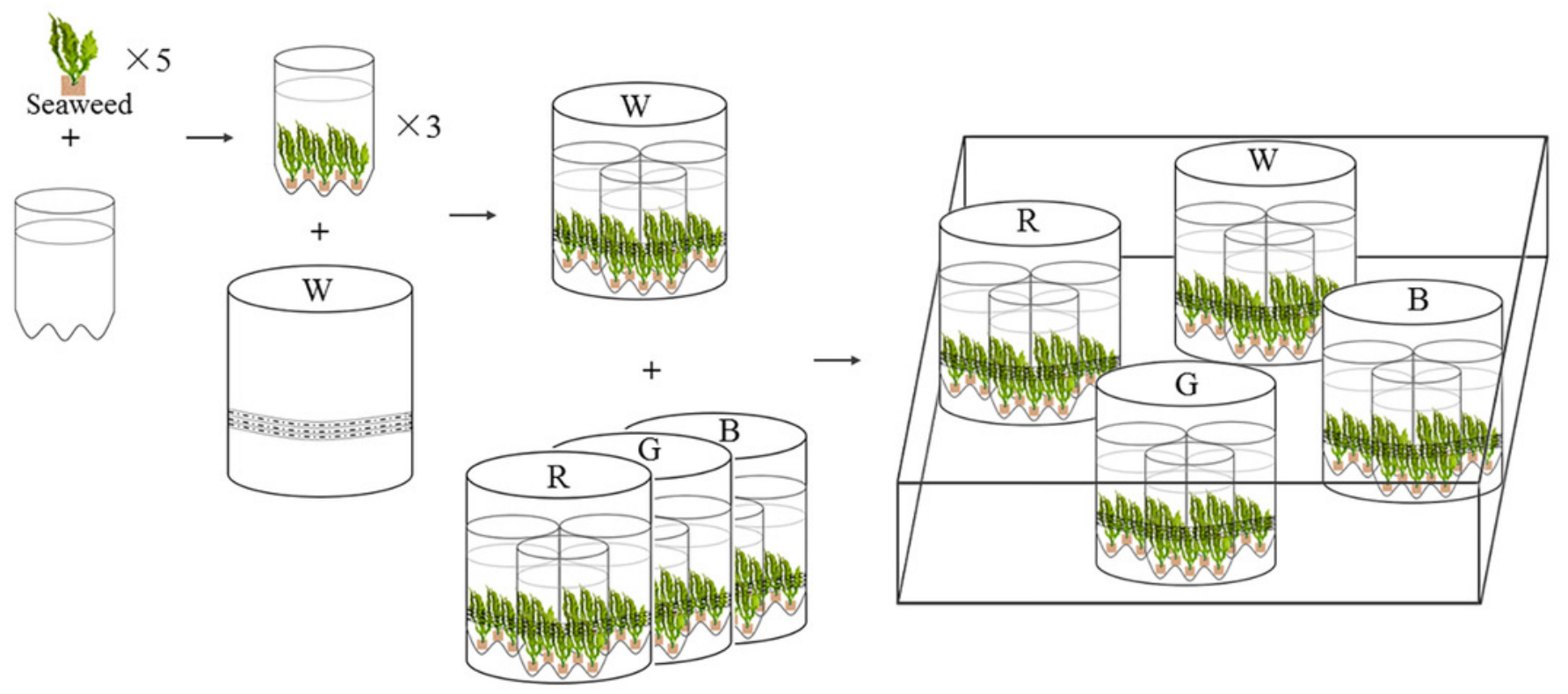
Figure 2

Emission spectral distribution of the the white, red, green and blue LEDs light sources

(A) Red, green, blue LEDs (B) White LEDs 


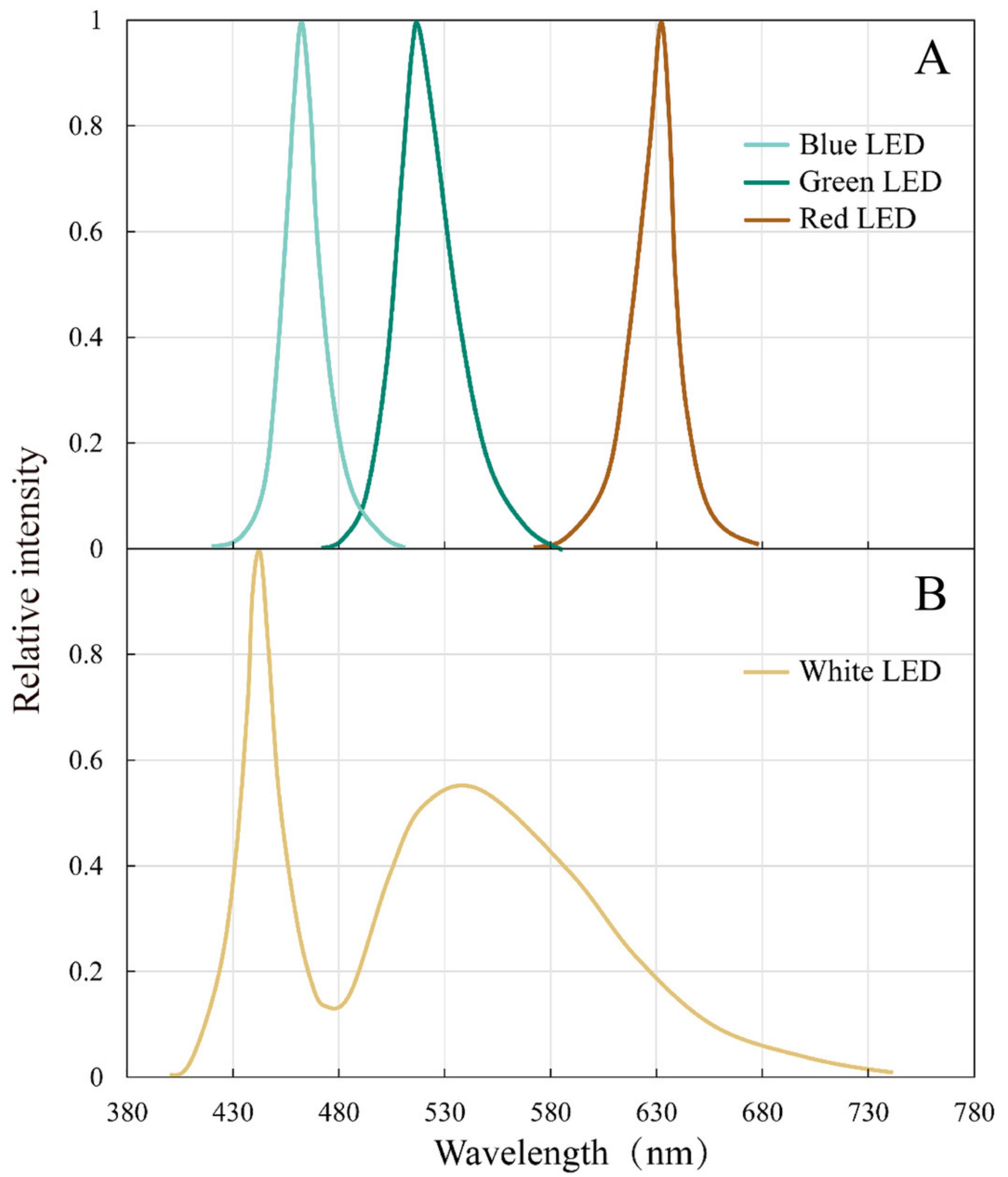


Figure 3

Specific growth rate (SGR) of $U$. pertusa and S. fusiforme after 18 days cultivation under various LEDs

(A) SGR of U. pertusa (B) SGR of S. fusiforme 


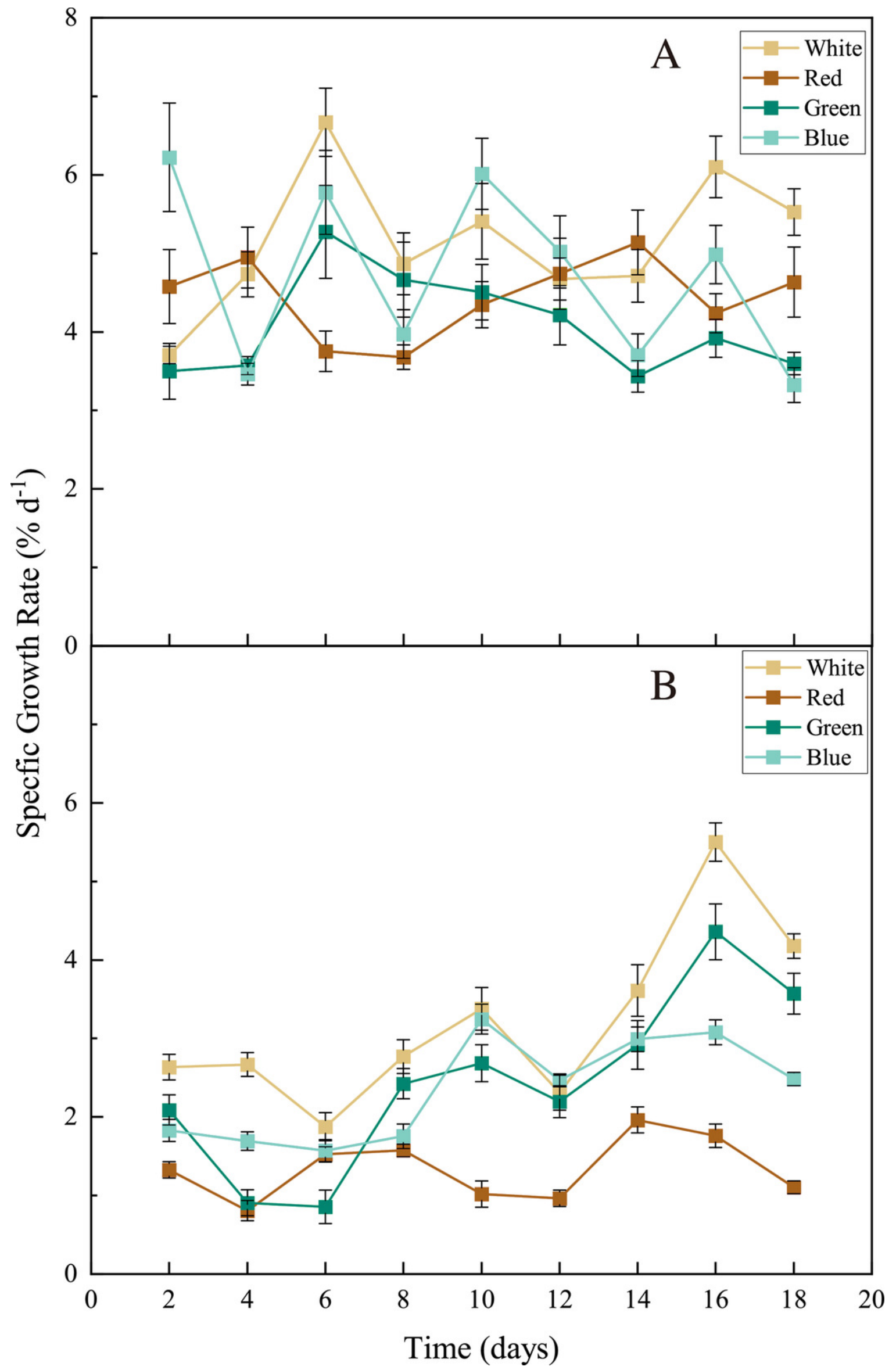

Peer) reviewing PDF | (2019:12:44139:3:0:NEW 1 Apr 2021) 
Figure 4

Pigments concentrations of $U$. pertusa and $S$. fusiforme after 18 days cultivation under various LEDs

(A) Chlorophyll a concentration of $U$. pertusa (B) Carotenoid concentration of $U$. pertusa (C)

Chlorophyll a concentration of $S$. fusiforme (D) Carotenoid concentration of $S$. fusiforme
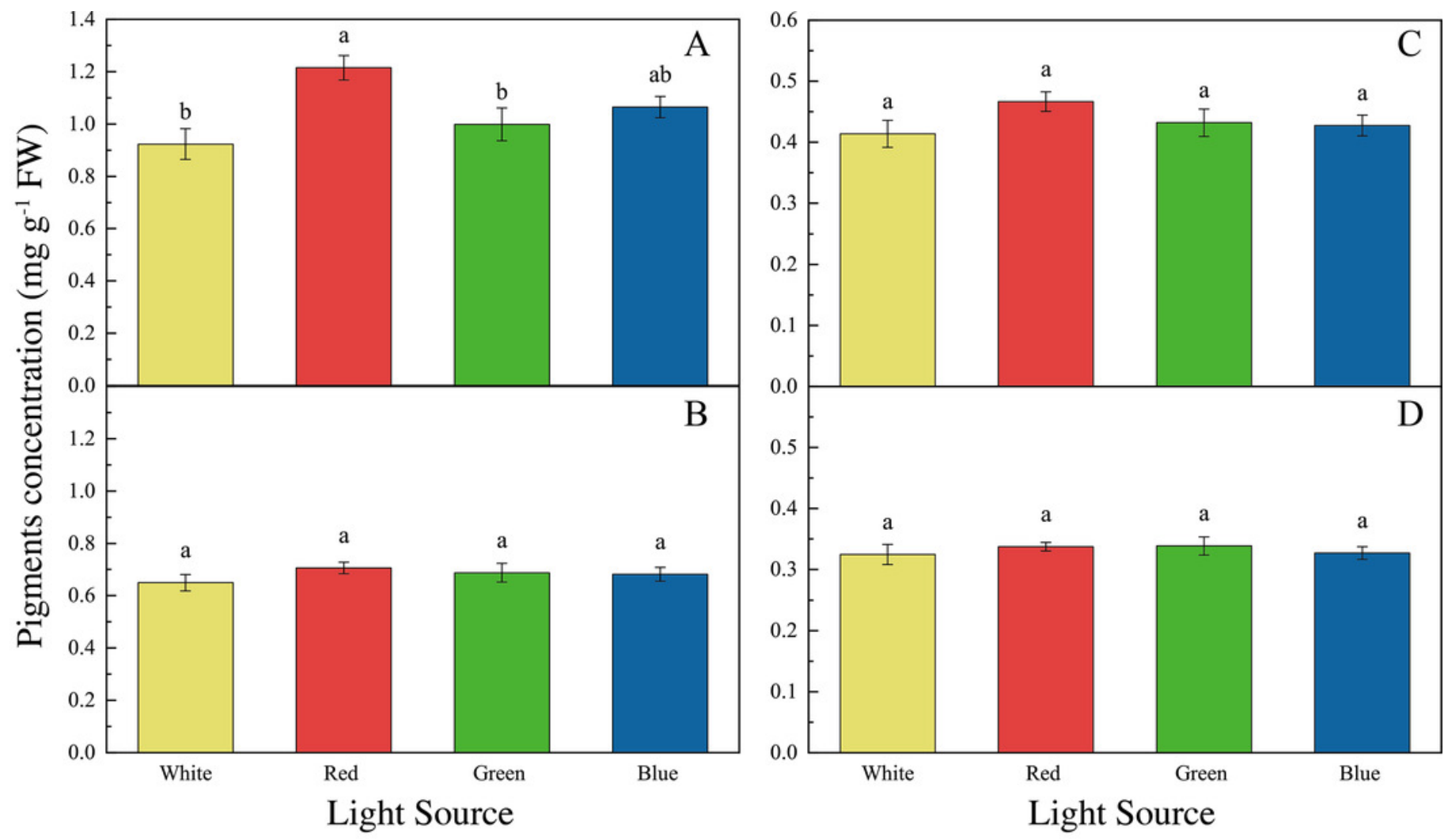
Figure 5

Soluble protein concentrations of $U$. pertusa and $S$. fusiforme after 18 days cultivation under various LEDs

(A) Soluble protein concentration of $U$. pertusa (B) Soluble protein concentration of $S$. fusiform 


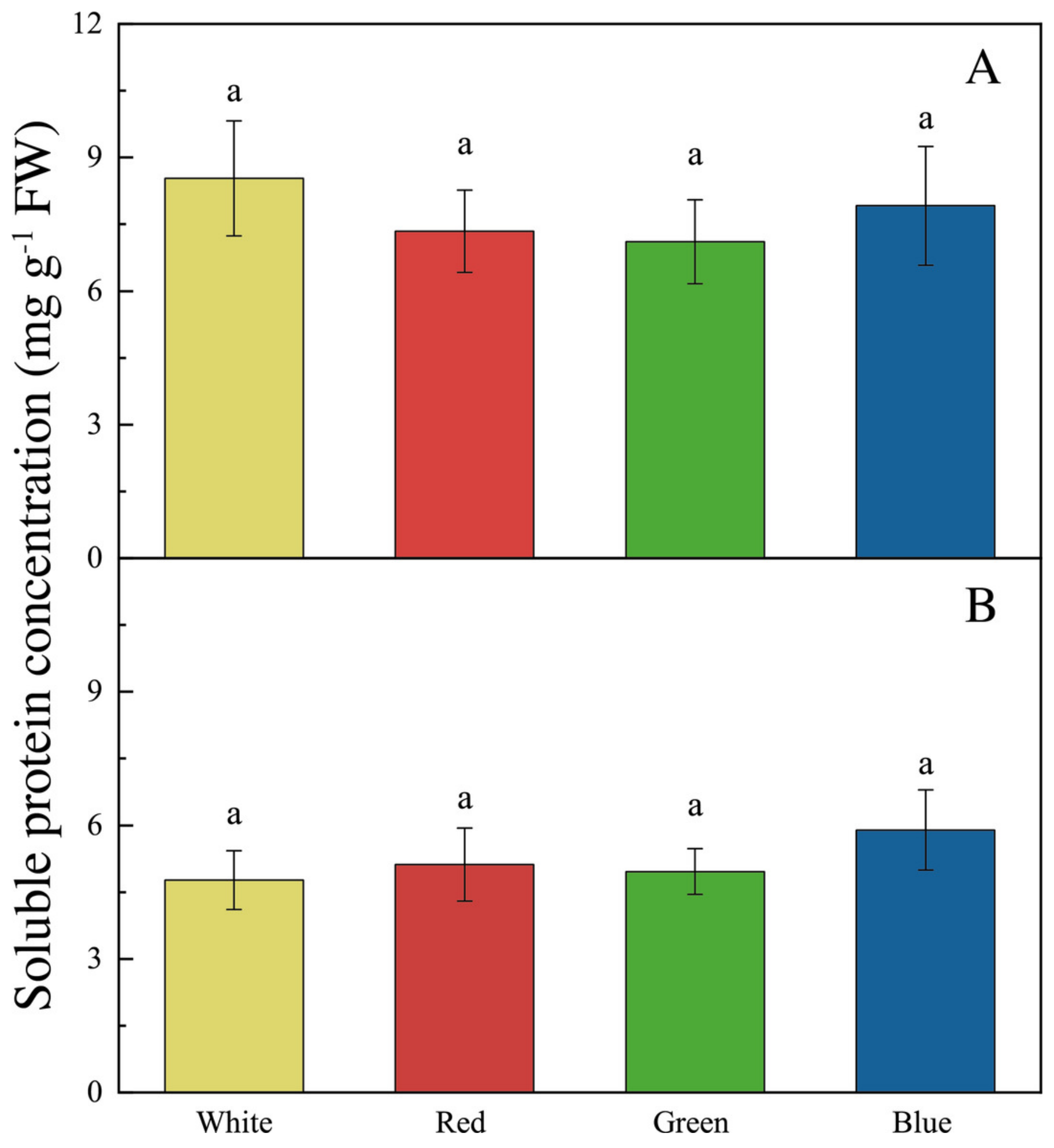

